\title{
The Revelation of Various Compounds Found in Nigella sativa $L$. (Black Cumin) and Their Possibility to Inhibit COVID-19 Infection Based on the Molecular Docking and Physical Properties
}

\author{
Yaseen Ismail Shaikh, ${ }^{2, *}$ Viquar Sameer Shaikh, ${ }^{1,3}$ Khursheed Ahmed, ${ }^{2}$ Gulam M. Nazeruddin ${ }^{2}$ and Habib M. Pathan ${ }^{1}$
}

\begin{abstract}
As there is no specified drug available to fight COVID-19, it is essential to have a different strategy to fight this virus. In the present study, using molecular docking, we have identified possible protease inhibitors of COVID-19 by the molecules present in Nigella sativa L. (black cumin), which is a reputed healing herb extensively used for processing Ayurvedic and Unani remedies. Herein, we perform molecular docking and study of various physical properties/descriptors of four derivatives of thymoquinone found in the essential oil of the said seeds and they are compared with the docking results of chloroquine to determine its potential against COVID-19 infection.
\end{abstract}

Keywords: Black Cumin, COVID-19, Spike protein, Molecular Docking, Anti-COVID-19 drugs.

Received: 2 June 2020; Accepted: 3 July 2020.

Article type: Research article.

\section{Introduction}

COVID-19 is a disease caused by the $\beta$ type of coronavirus (SARS-CoV-2) from the family Coronaviridae, which was recently identified as a novel virus in a patient who showed the symptoms of pneumonia. This is a highly infectious disease responsible for the pandemic caused throughout the world today. Further, as this virus is novel, so, till date, neither vaccination nor any drug available to treat this disease. Discovery of a new drug even though the silico-chemicobiological approach ${ }^{[1,2]}$ is not advisable in the present situation because of time constraints and fatality rates. This outbreak of coronavirus disease 2019 (COVID-19) triggered by the severe acute respiratory syndrome coronavirus 2 (SARS-CoV-2) poses a severe threat to worldwide public health. ${ }^{[3]}$ On 30th January 2020, the World Health Organization (WHO) officially broadcasted COVID-19 as the public health emergency of international concern. ${ }^{[4]}$ According to the situation report of WHO dated $26^{\text {th }}$ May 2020, the number of infected cases reported across the globe was 54,04,512 and around 3,43,514 deaths. ${ }^{[5]}$ As of now, there is no specific drug

\footnotetext{
${ }^{1}$ Advanced Physics Laboratory, Department of Physics,Savitribai Phule Pune University, Pune - 411007.

${ }^{2}$ Department of Chemistry, Abeda Inamdar Sr. College, Pune-1.

3Department of Chemistry, Nowrosjee Wadia College, Pune-1.

*E-mail: sheray2k@gmail.com (Y. I. Shaikh).
}

or vaccine for the treatment or prevention of the COVID-19. The current crisis management includes travel restrictions, patient isolation, and supportive medical care. Such massive numbers of infected and dead people demand a crucial demand for effective, available, and affordable drugs to control and reduce the epidemic. In this current scenario, the researchbased pharmaceutical industry has increasingly employed modern medicinal chemistry methods, including molecular modeling, as powerful tools for the study of structure-activity relationships (SAR) ${ }^{[6]}$ Molecular docking is one of the most frequently used methods in structure-based drug design (SBDD) because of its ability to predict, with a large degree of accuracy, the conformation of small-molecule ligands within the proper target binding site. ${ }^{[7]}$ Nowadays, it has become an essential tool for drug discovery. ${ }^{[8]}$

Furthermore, molecular docking algorithms give results for quantitative predictions of binding energetics, providing rankings of docked compounds based on the binding affinity of ligand-receptor complexes with pharmacokinetic properties (ADMET: absorption, distribution, metabolism, excretion, and toxicity). ${ }^{[8-10]}$ The chloroquine (CQ) is easily available and has a low cost, but an overdose of CQ can cause acute poisoning and death. ${ }^{[11]}$ We have to devise a different strategy to fight this virus. So we have decided to search such herbs which are commonly used against various diseases in Ayurvedic/Unani literature or some common allopathic drugs, 
which have some similarity to chloroquine. In Islamic literature particularly in Tib-e-Nabvi (Prophetic Medicine) ${ }^{[12]}$ the seeds of Nigella sativa L. (black cumin) are considered as one of the greatest forms of healing medicine. ${ }^{[13]}$ So, it was decided to perform molecular docking and study various physical properties/descriptors of four derivatives of thymoquinone ${ }^{[14]}$ found in the essential oil of the said seeds. These results were compared with chloroquine, ${ }^{[15-17]}$ presently used against this virus. The two chemical structures and their mechanisms acting as a weak base and immune modulator. So both drugs may have the potential to treat SARS-CoV-2. To make the above discussion clear, we have docked chloroquine with the SARS-CoV-2 Spike protein receptor binding as the target. Fig. 1 shows the structure of chloroquine.<smiles>CCN(CC)CCCC(C)Nc1ccnc2cc(Cl)ccc12</smiles>

Fig.1. Structure of chloroquine (CQ)<smiles>CCC1=CC(=O)C(C)=CC1=O</smiles>

Thymoquinone (TQ)<smiles>CCc1ccc(C)cc1O</smiles>

Thymol (THY)<smiles>CCc1cc(O)c(C)cc1O</smiles>

Thymohydroquinone (THQ)

The receptor-binding domain on the spike protein of SARS$\mathrm{CoV}-2$ is considered as the target for this docking analysis.

\section{Results and Discussion}

The docking studies of CQ, DTQ, THQ, THY, and TQ against the SARS-CoV-2 receptor-binding domain complexed with its receptor (PDB ID: 2AJF) exposed the interaction of the following:

Chloroquine with TYRE: 494, VALE: 394, SERE: 362, ILEE: 489 as illustrated in Fig.3A. Also, the negative value of binding energy i.e. $(-4.01 \mathrm{Kcal} / \mathrm{mol})$ suggests the stability of the complex. (Table 1).

Dithymoquinone with ASNE: 427, ILEE: 428 as illustrated in Fig.4A. Fig.2 shows the structure of different molecules used for docking. Also, the negative value of binding energy i.e. $(-7.19 \mathrm{Kcal} / \mathrm{mol})$ suggests the stability of the complex. (Table 1).

Thymohydroquinone with GLYE: 391, SERE: 362, VALE: 394, TYRE: 494, ARGE: 395 as illustrated in Fig.5A. Also, the negative value of binding energy i.e. $(-4.89 \mathrm{Kcal} / \mathrm{mol})$ suggests the stability of the complex. (Table 1).

Thymol with PHEE: 329, TRPE: 423, PHEE: 360, PHEE: 361 as illustrated in Fig.6A. Also, the negative value of binding energy i.e. $(-4.46 \mathrm{Kcal} / \mathrm{mol})$ suggests the stability of the complex. (Table 1).

Thymoquinone with ASNE: 424, SERE: 362, PHEE: 360, TRPE: 423 as illustrated in Fig.7A. Also, the negative value of binding energy i.e. $(-4.98 \mathrm{Kcal} / \mathrm{mol})$ suggests the stability of the complex. (Table 1 ).

Table 1. Docking results of CQ, DTQ, THQ, THY, and TQ compounds targeting the receptor-binding domain of SARSCoV-2 (PDB ID: 2AJF) for anti-coronavirus activity.

\begin{tabular}{|c|c|c|c|}
\hline $\begin{array}{c}\text { Comp- } \\
\text { ound } \\
\text { Name }\end{array}$ & $\begin{array}{c}\text { Compound } \\
\text { Structure }\end{array}$ & $\begin{array}{c}\text { Binding } \\
\text { energy } \\
\text { (Kcal/mol) }\end{array}$ & $\begin{array}{c}\text { Predicted } \\
\text { IC50 value }\end{array}$ \\
\hline CQ & & -4.01 & $\begin{array}{c}1.14 \\
\mathrm{mM}\end{array}$ \\
\hline DTQ & & -7.19 & $\begin{array}{c}5.41 \\
\mu \mathrm{M}\end{array}$ \\
\hline THQ & & -4.89 & $\begin{array}{c}\mu \mathrm{M} \\
\text { THY }\end{array}$ \\
& & -4.46 & $\mu \mathrm{M}$ \\
\hline & & & 223.08 \\
TQ & & -4.98 & $\mu \mathrm{M}$ \\
\hline
\end{tabular}

\section{Computational Work}

\subsection{Docking Methodology}

The practice of molecular docking is useful in yielding valuable information for designing ligands for known active sites of the macromolecules like proteins. For docking analysis, AutoDock 4.2 was employed using the quality protocol mentioned in the literature. ${ }^{[18-20]}$ The X-ray crystal structure of the target protein was retrieved from the RCSB protein data bank. ${ }^{[21]}$ Macromolecule having PDB ID: 2AJF, which is the structure of the SARS coronavirus spike receptor-binding domain complexed with its receptor. ${ }^{[21]}$ We docked CQ, DTQ, THQ, THY, and TQ with the PDB ID: 2AJF. Also, the property-based approach was achieved using DataWarrior (version 5.2.1) for the prediction of ADMET properties. ${ }^{[22]}$ 
Chloroquine (CQ) compound docking interactions with SARS-CoV-2 receptor-binding domain (PDB ID: 2AJF) for anti-coronavirus activity.
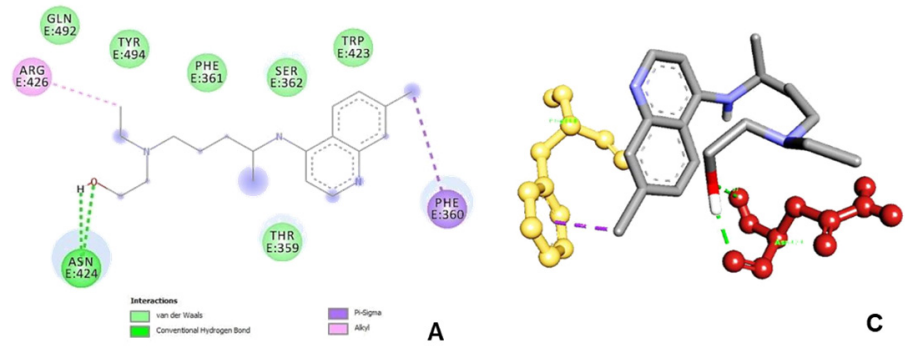

A
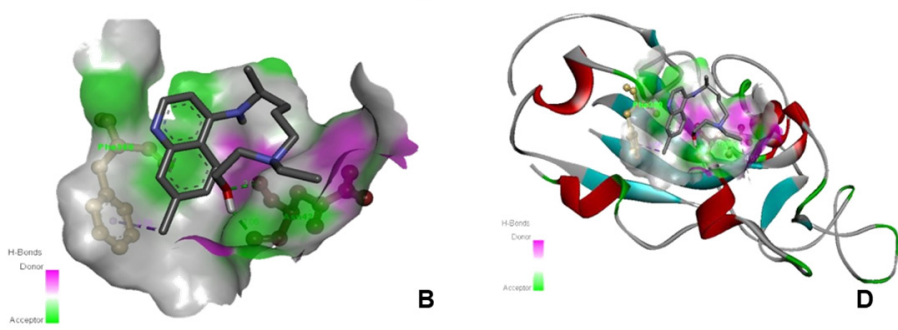

Fig. 3 Conformational changes observed due to the binding of ligand CQ (Chloroquine), with PDB ID: 2AJFA) represents 2D interactions of $\mathrm{CQ}, \mathrm{B})$ represents $3 \mathrm{D}$ interactions formed by the CQ, Whereas, C, D) represent (s) surface area interactions of CQ with receptor binding domain of SARSCoV-2.

Dithymoquinone DTQ compound docking interactions with SARS-CoV-2 receptor-binding domain (PDB ID: 2AJF) for anti-coronavirus activity.

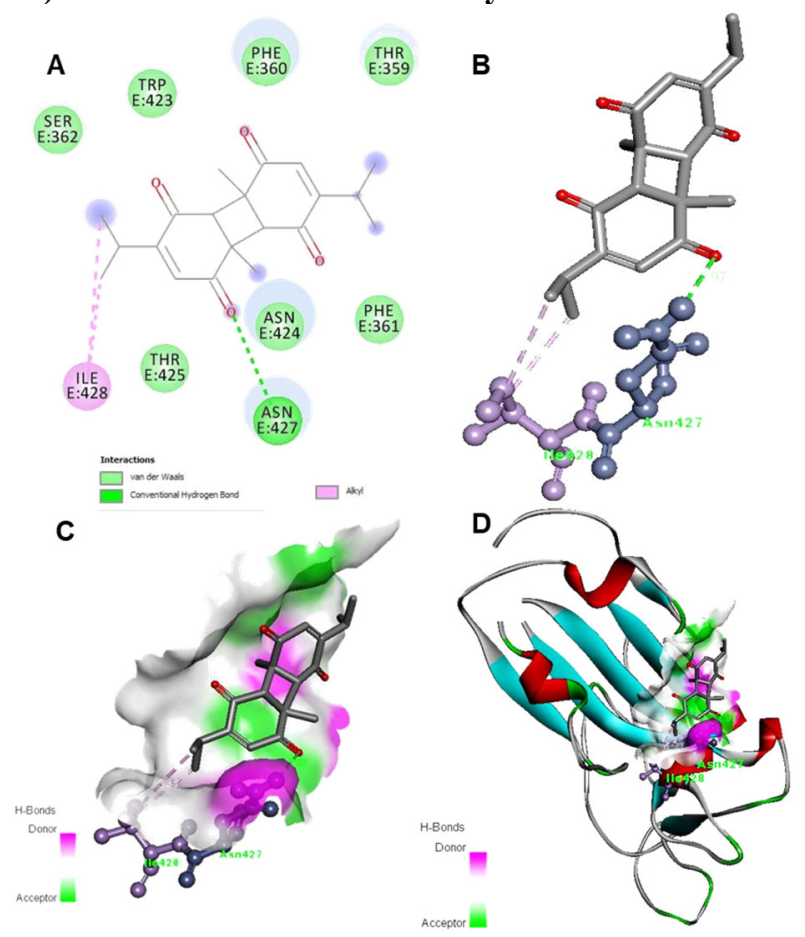

Fig. 4 Conformational changes observed due to the binding of ligand DTQ with PDB ID: 2AJFA) represents 2D interactions of DTQ, B) represents 3D interactions formed by the DTQ, whereas C, D) represents surface area interactions of DTQ with receptor binding domain of SARS-CoV-2.
Thymohydroquinone (THQ) compound docking interactions with SARS-CoV-2 receptor-binding domain (PDB ID: 2AJF) for anti-coronavirus activity.

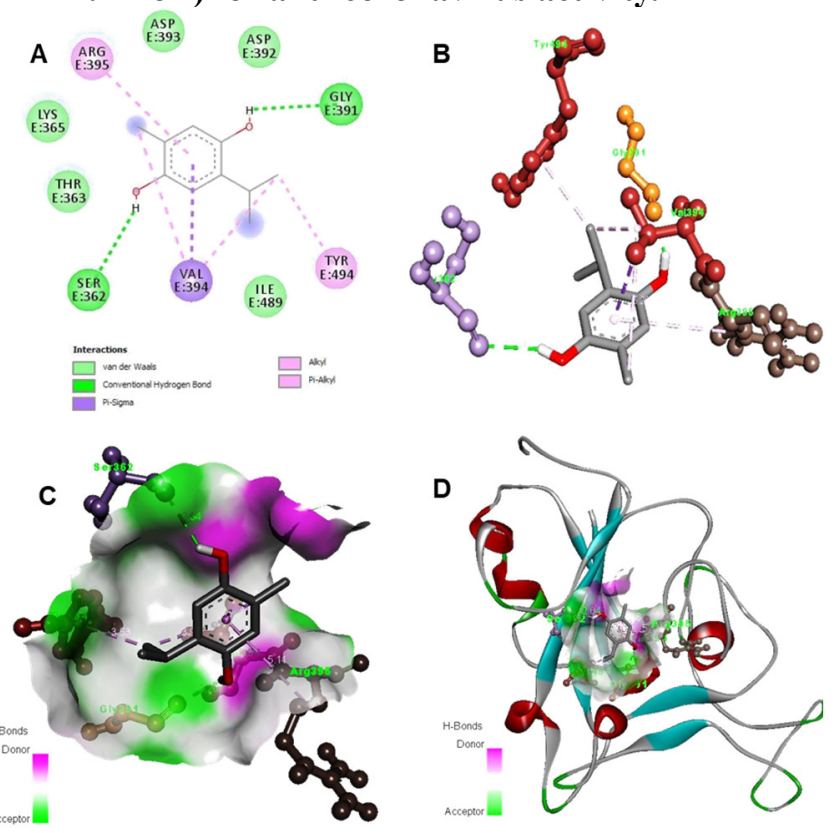

Fig. 5 Conformational changes observed due to the binding of ligand THQ with PDB ID: 2AJFA) represents 2D interactions of THQ, B) represents 3D interactions formed by the THQ, Whereas, C, D) represents surface area interactions of THQ with receptor binding domain of SARS-CoV-2.

Thymol (THY) compound docking interactions with SARS-CoV-2 receptor-binding domain (PDB ID: 2AJF) for anti-coronavirus activity.

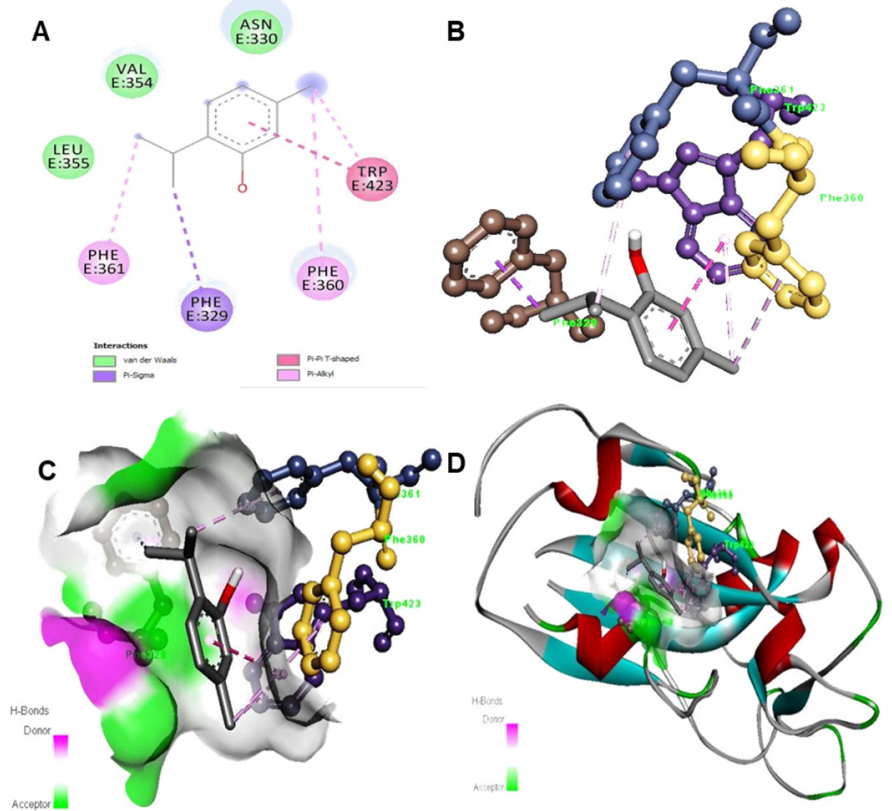

Fig. 6 Conformational changes observed due to the binding of ligand THY with PDB ID: 2AJFA) represents 2D interactions of THY, B) represents 3D interactions formed by the THY, whereas C, D) represent(s) surface area interactions of THY with receptor binding domain of SARS-CoV-2. 
Thymoquinone (TQ) compound docking interactions with SARS-CoV-2 receptor-binding domain (PDB ID: 2AJF) for anti-coronavirus activity.

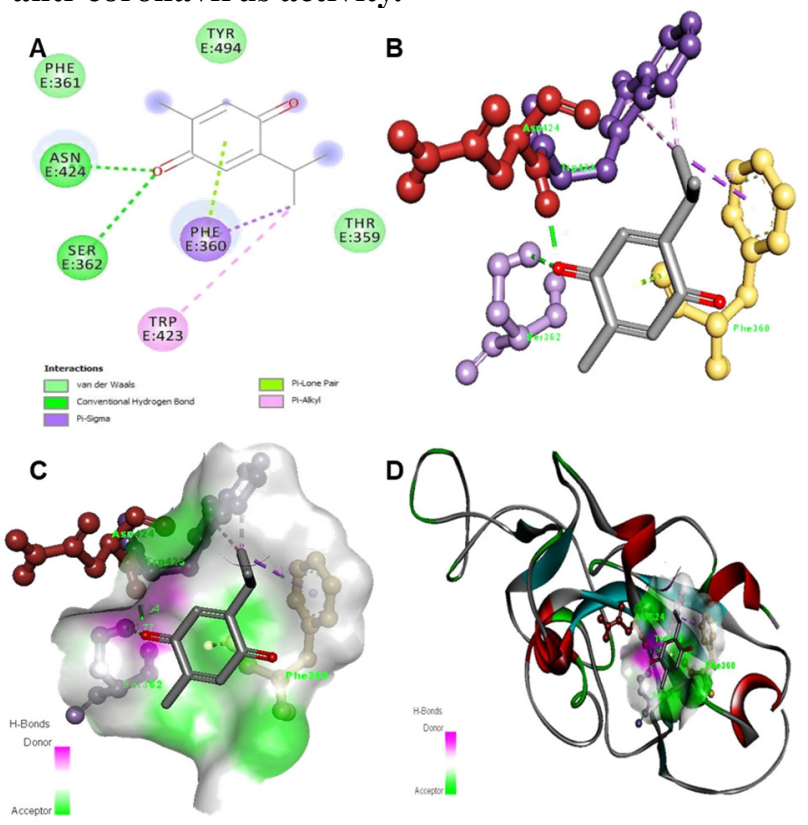

Fig. 7 Conformational changes observed due to the binding of ligand TQ with PDB ID: 2AJFA) represents 2D interactions of $T Q$, B) represents 3D interactions formed by the TQ, whereas C, D) represent(s) surface area interactions of TQ with receptor binding domain of SARS-CoV-2.

\section{Evaluation of Binding Energy}

The strength of a protein-ligand complex is set forth to the intermolecular interactions between these binding partners, solvent effects, and dynamics. So, by employing all-atom molecular dynamics (MD) simulations, we are capable to test all of those together. But, to avert the different computational costs linked to these simulations, molecular docking use scoring functions to grant a rapid and simple evaluation of the binding dynamics of the expected ligand-receptor complexes. ${ }^{[23-24]}$ The docking results of the binding energy of CQ, DTQ, THQ, THY, and TQ are stated in Table 1. We subdivide the ADMET parameters of CQ, DTQ, THQ, THY, and TQ as ADME* and Toxicology in Table 2 and Table 3.

\section{Important note}

According to the docking results, compound DTQ has shown the best binding energy of $-7.19 \mathrm{kcal} / \mathrm{mol}$ with a predicted IC50 value of $5.41 \mu \mathrm{M}$ (micromolar) compared to $\mathrm{CQ}$, which has shown $-4.01 \mathrm{kcal} / \mathrm{mol}$ binding energy with $1.14 \mathrm{mM}$ (millimolar) of predicted IC50 value. It can be stated that more negative binding energy is better for the ligand as well as the complex. On the other hand, Data Warrior (version 5.2.1) is the software used for generating ADMET properties, and according to predicted ADME parameters based on Lipinski's rule of five DTQ is the closest to CQ with no toxic profiling.

Table 2. ADME* parameters of the present studied compounds.

\begin{tabular}{|c|c|c|c|c|c|c|c|c|}
\hline $\begin{array}{c}\text { Compound } \\
\text { code }\end{array}$ & $\begin{array}{c}\text { Molecular } \\
\text { Formula }\end{array}$ & Mol.Wt. & Log P & $\begin{array}{c}\text { H-bond } \\
\text { donors }\end{array}$ & $\begin{array}{c}\text { H-Bond } \\
\text { acceptors }\end{array}$ & $\begin{array}{c}\text { Rotatable } \\
\text { bonds }\end{array}$ & TPSA & $\begin{array}{c}\text { ADME } \\
\text { pass/fail }\end{array}$ \\
\hline CQ & $\mathrm{C}_{18} \mathrm{H}_{26} \mathrm{~N}_{3} \mathrm{Cl}$ & 319.878 & 4.0091 & 1 & 3 & 8 & 28.16 & PASS \\
\hline DTQ & $\mathrm{C}_{20} \mathrm{H}_{24} \mathrm{O}_{4}$ & 328.407 & 2.7312 & 0 & 4 & 2 & 68.28 & PASS \\
\hline THQ & $\mathrm{C}_{10} \mathrm{H}_{14} \mathrm{O}_{2}$ & 166.219 & 2.4991 & 2 & 2 & 1 & 40.46 & PASS \\
\hline THY & $\mathrm{C}_{10} \mathrm{H}_{14} \mathrm{O}$ & 150.22 & 2.8448 & 1 & 1 & 1 & 20.23 & PASS \\
\hline TQ & $\mathrm{C}_{10} \mathrm{H}_{12} \mathrm{O}_{2}$ & 164.203 & 1.6375 & 0 & 2 & 1 & 34.14 & PASS \\
\hline
\end{tabular}

\#( Topological Polar Surface Area)

Table 3. Toxicology profile for the present studied compounds.

\begin{tabular}{|c|c|c|c|c|}
\hline $\begin{array}{c}\text { Com- } \\
\text { pound } \\
\text { Name }\end{array}$ & $\begin{array}{c}\text { Muta- } \\
\text { genic }\end{array}$ & $\begin{array}{c}\text { Tumor- } \\
\text { igenic }\end{array}$ & $\begin{array}{c}\text { Effect on } \\
\text { Reproduc- } \\
\text { tive system }\end{array}$ & $\begin{array}{c}\text { Eye Ir- } \\
\text { ritant }\end{array}$ \\
\hline CQ & HIGH & NONE & NONE & HIGH \\
\hline DTQ & NONE & NONE & NONE & NONE \\
\hline THQ & HIGH & LOW & NONE & NONE \\
\hline THY & HIGH & NONE & HIGH & NONE \\
\hline TQ & HIGH & NONE & NONE & NONE \\
\hline
\end{tabular}

\section{Conclusion}

The objective of this study was to identify the molecules from Nigella sativa L.; powder of the black cumin seeds or oil of these seeds, which may hinder COVID-19 by acting on the receptor-binding site of SARS-CoV-2 (PDB ID: 2AJF). The results of molecular docking show that dithymoquinone, thy- mohydroquinone, thymol, thymoquinone from this medicinal plant may inhibit COVID-19 infection giving the same or better energy score compared to chloroquine. Powder of black cumin seeds or its oil can be preferred, as Ayurvedic/Unani medicine does not have side effects. Those results encourage further in vitro and in vivo investigations and also encourage traditional use of Nigella sativa L. prophylactically.

\section{Acknowledgments}

Authors are thankful to Advanced Physics Laboratory, Department of Physics, Savitribai Phule Pune University Pune - 411007 for assistance. Similarly, we are also thankful to Innovative informatics Technologies, Miyapur Hyderabad, India for their help in the analysis of docking studies and physical properties. 


\section{Conflict of Interest}

There is no conflict of interest.

\section{Supporting Information}

Not Applicable.

\section{References}

[1] H. Van de Waterbeemd andE.Gifford, Nat. Rev. Drug Discov., 2003, 2,192-204, doi: 10.1038/nrd1032.

[2] N. Kumar, B. S. Hendriks, K.A. Janes, D. de Graaf and D.A. Lauffenburger, Drug Discov. Today, 2006, 11, 806-811, doi: 10.1016/j.drudis.2006.07.010.

[3] C. Wu, Y. Liu, Y. Yang, P. Zhang, W. Zhong, Y. Wang, Q. Wang, Y. Xu, M. Li, X. Li, M. Zheng, L. Chen and H. Li, Acta Pharm. Sin. B, 2020, 10, 766-788, doi: 10.1016/j.apsb.2020.02.008

[4] X. Li, W. Wang, X. Zhao, J. Zai, Q. Zhao, Y. Li and A. Chaillon, J. Med. Virol., 2020,92(5),501-511, doi: 10.1002/jmv.25701.

[5] WHO Situation report dated $26^{\text {th }}$ May 2020. Available on https://www.who.int/docs/default-

source/coronaviruse/situation-reports/20200526-covid-19sitrep-127.pdf?sfvrsn=7b6655ab 8 .

[6] J. Weigelt,Exp. Cell Res., 2010, 316, 1332-1338, doi: 10.1016/j.yexcr.2010.02.041.

[7] X.Y. Meng, H.X. Zhang, M. Mezei and M. Cui, Curr. Comput. Aided Drug Des., 2011, 7, 146-157, doi: 10.2174/157340911795677602.

[8] F. López-Vallejo, T. Caulfield, K. Martínez-Mayorga, M. A. Giulianotti, A. Nefzi, R. A. Houghten and J. L. MedinaFranco, Comb. Chem. High Throughput Screen, 2011, 14, 475 487, doi: 10.2174/138620711795767866.

[9] S. Y. Huang and X. Zou, Int. J. Mol. Sci, 2010, 11, 30163034, doi: 10.3390/ijms11083016.

[10] C. A. Lipinski, F. Lombardo, B. W. Dominy and P. J. Feeney,Adv. Drug Deliv. Rev, 2012, 64, 4-17, doi: 10.1016/j.addr.2012.09.019.

[11] Weniger, H \& World Health Organization. (1979). Review of side effects and toxicity of chloroquine / by $\mathrm{H}$. Weniger. Geneva : World health Organization. https://apps.who.int/iris/handle/10665/65773.
[12] Al-Bukhari MI, Sahi Al-Bukhari The collection of authentic sayings of Prophet Mohammad (peace be upon him), division 71 on medicine, 2nd ed. Ankara, HilalYayinlari, 1976. [13] A. Ahmad, A. Husain, M.Mujeeb, S. A. Khan, A.K.Najmi, N. A. Siddique, Z. A. Damanhouri and F. Anwar, Asian Pac. J. Trop. Biomed., 2013, 3(5), 337-352, doi: 10.1016/S2221-1691(13)60075-1.

[14] S. K. T. Venkatachallam, H. Pattekhan, S. Divakar and U. S. Kadimi, J. Food Sci. Technol., 2010, 47(6), 598-605, doi: 10.1007/s13197-010-0109-y.

[15] E. Keyaerts, L. Vijgen, P. Maes, J. Neyts and M. V. Ranst, Biochem.Biophys. Res.Commun.,2004, 323(1), 264-268, doi: 10.1016/j.bbrc.2004.08.085.

[16] M. Kono, K. Tatsumi, A. M. Imai, K. Saito, T. Kuriyama and H. Shirasawa, Antiviral Res., 2008, 77, 150-152, doi: 10.1016/j.antiviral.2007.10.011.

[17] E. Keyaerts, S. Li, L. Vijgen, E. Rysman, J. Verbeeck, M. Van Ranst and P. Maes, Antimicrob. Agents Chemother., 2009, 53, 3416-3421, doi: 10.1128/AAC.01509-08.

[18] R. Huey, G. M. Morris, A. J. Olson and D. S. Goodsell, J.Comput. Chem., 2007, 28, 1145-1152, doi: $10.1002 /$ jcc. 20634.

[19] G. M. Morris, R. Huey, W. Lindstrom, M. F. Sanner, R. K. Belew, D. S. Goodsell and A. J. Olson, J. Comput. Chem., 2009, 30, 2785-2791, doi: 10.1002/jcc.21256.

[20] G. M. Morris, D. S. Goodsell, R.S. Halliday, R. Huey, W. E. Hart, R. K. Belew and A. J. Olson, J. Comput. Chem., 1998, 19, 1639-1662, doi: 10.1002/(SICI)1096987X(19981115)19:14<1639::AID-JCC10>3.0.CO;2-B.

[21] F. Li, W. Li, M. Farzan and S.C. Harrison, Science, 2005, 309(5742), 1864-1868, doi: 10.1126/science. 1116480.

[22] T. Sander, J.Freyss, M. von Korff and C.Rufener, J. Chem. Inf. Model., 2015, 55(2), 460-473, doi: 10.1021/ci500588j.

[23] N. Foloppe, R. Hubbard and N. Foloppe, Curr. Med. Chem.,2006, 13, 3583-3608, doi: 10.2174/092986706779026165.

[24] A. N. Jain, Curr. Protein Pept. Sci., 2006, 7, 407-420, doi: $10.2174 / 138920306778559395$.

Publisher's Note Engineered Science Publisher remains neutral with regard to jurisdictional claims in published maps and institutional affiliations. 